\title{
COOPERATIVA-ESCOLA NAS ESCOLAS TÉCNICAS AGRÍCOLAS
}

\author{
P.V. MARQUES \\ Departamento de Economia e Sociologia Rural, ESALQ-USP - C.P. 9, CEP: 13418-900 - Piracicaba,SP. \\ H.G. LOVE' \\ University of Kentucky, Lexington, Kentucky, U.S.A.
}

\begin{abstract}
RESUMO: A dificuldade de gerenciar recursos e proporcionar melhores condições de ensino para os estudantes são algumas das deficiencias das Escolas Técnicas Agrícolas (ETAs) brasileiras, problemas parcialmente superados por algumas escolas que adotaram a chamada Cooperativa-Escola. Neste trabalho, procura-se discutir alguns aspectos filośficos referentes às ETAs e como a Cooperativa-Escola pode ajudar a solucionar seus principais problemas educativos e administrativos; um estudo de caso utilizando-se a técnica de auditoria administrativa foi desenvolvido numa ETA cuja Cooperativa-Escola é considerada um modelo de bom funcionamento e alguns procedimentos foram descritos, objetivando-se estender a prática de Cooperativa-Escola para outras escolas técnicas agrícolas brasileiras. Descritores: Escola Técnica Agrícola, Cooperativa-Escola, Auditoria Administrativa
\end{abstract}

\section{COOPERATIVE-SCHOOL AT TIE AGRICULTURAL TECHNICAL SCHOOLS}

\begin{abstract}
Some of the problems with the Brazilian public Agricultural Technical School systems (ETAs) are related to resource management and the need to improve teaching and learning conditions. Those deficiencies were partially corrected after setting up Cooperative-Schools that allow the ETAs to raise and to administrate funds. Administrative procedures of the ETAs and how the Cooperative-School could help solving their main educational and adminsitrative problems are discussed in this research. A case study using the management audit technique was developed in one ETA with a well known Cooperative-School. Some observed procedures are described with the intention of extending the practice of Cooperative-Schools to other Brazilian Agricultural Technical Schools.
\end{abstract}

Key Words: Agricultural Technical School, Cooperative-School, Management Audit.

\section{INTRODUÇÃO}

O Brasil ainda é um país que depende basicamente da agricultura, com cerca de $37 \%$ da sua população vivendo na zona rural. A busca de competividade do setor e a existência de um mercado consumidor cada vez mais exigente, faz com que se necessite de uma mão-de-obra com razoável grau de especialização, que pode ser suprida pela rede de ensino técnico agrícola existente no país.

O projeto "Desenvolvimento Rural Integrado" (DRI) (ESALQ, 1991), objetiva utilizar as ETAs do Estado de São Paulo como instrumento de desenvolvimento integrado da agricultura. Este projeto está inicialmente sendo desenvolvido no Estado e o contacto com as ETAs permitiu observar os pontos fortes e fracos do sistema.

\footnotetext{
${ }^{1}$ Bolsista da FAPESP.
}

Sci. agric., Piracicaba, 50(3):509-516, out./dez., 1993
Uma das deficiências das ETAs é a dificuldade de gerenciar recursos e proporcionar melhores condições de ensino para os estudantes, problema parcialmente superado por algumas ETAs que adotaram a chamada Cooperativa-Escola.

Neste trabalho se procurará discutir alguns aspectos filosóficos sobre as ETAs e como a Cooperativa-Escola pode ajudar a solucionar os seus principais problemas educativos e administrativos.

A discussão dos problemas gerais das ETAS será baseado no trabalho do projeto DRI com as ETAs do Estado de São Paulo; a discussão da importância e aspectos operacionais da Cooperativa-Escola, será baseada em informações obtidas na Escola Técnica Federal de Inconfidentes, Minas Gerais, um modelo de bom funcionamento da Cooperativa-Escola. 


\section{ESCOLAS TÉCNICAS AGRÍCOLAS}

\section{Objetivos das ETAs}

Uma Escola Técnica Agrícola tem por objetivos formar alunos aptos a desempenhar a profissão de técnico agrícola, utilizando para isto técnicas educacionais e de treinamento.

Do ponto de vista educacional, a ETA necessita fornecer-lhes os conhecimentos comuns de um aluno de $2^{\circ}$ grau (português, matemática, geografia, história, etc.), além da teoria necessária para dominar os princípios técnicos específicos. Para atingirem estes objetivos, as ETAs contam com professores do núcleo comum (ou discíplinas não técnicas comuns aos demais alunos de $2^{\circ}$ grau) e professores da área técnica (agricultura, zootecnia, etc.).

As ETAs devem educar e treinar alunos nos vários aspectos da ciência e da agricultura aplicada para lhes permitir desempenhar a contento suas atividades profissionais. Isto envolve um bom treinamento em línguas (português e inglês básico) e matemática. Além disto, espera-se que a escola proporcione meios para o desenvolvimento pessoal tais como o potencial de liderança e o sentido de cidadania.

Além do aspecto puramente escolar, a ETA deve também proporcionar ao aluno condições para aplicação prática dos conceitos vistos em classe. Este aspecto envolvendo mais treinamento do que educação propriamente dita, implica em proporcionar condições para que os alunos apliquem no campo o que aprenderam em aula. Como vão atuar numa agricultura cada vez mais empresarial, os alunos necessitam também ser treinados na aplicação de modernas técnicas administrativas.

\section{Qualidade da educação e do treinamento nas ETAs}

O aspecto educacional dos alunos deveria se desenvolver nas salas de aula e nos laboratórios. Nas salas de aula, os professores deveriam utilizarse de métodos de ensino que motivassem os alunos, tais como recursos audio-visuais, laboratórios, etc. Infelizmente, isto não acontece, e na maioria das vezes, os alunos são expostos a aulas expositivas e falhas sob o aspecto didático.

Os laboratórios deveriam servir para despertar a curiosidade $e$ aprofundar os conhecimentos desenvolvidos nas aulas teóricas.
Infelizmente, eles se encontram desaparelhados, com falta de material ou material inadequado $e$ com professores destreinados.

Os aspectos operacionais de treinamento deveriam ser desenvolvidos através de práticas apropriadas e representativas da realidade onde os alunos vão trabalhar. Infelizmente, isto nem sempre acontece dadas as condições precárias das instalações produtivas da maioria das escolas técnico-agrícolas.

Por se tratar de internato, os alunos deveriam também receber uma educação onde aspectos técnicos, humanos, alimentares e esportivos fossem harmonicamente equilibrados.

\section{BREVE HISTÓRICO E RAZÕES PARA EXIS- TÊNCIA DAS COOPERATIVAS-ESCOLA}

\section{Breve histórico}

A primeira cooperativa escolar surgiu no Brasil, no Estado de São Paulo, em 1932, tendo sido regulamentada em 1967 com o objetivo explícito de congregar alunos de um determinado estabelecimento de ensino e educá-los dentro dos princípios cooperativos. Até 1968 as cooperativas escolares funcionaram mais com o objetivo de simples fornecedoras de material escolar, não atendendo assim à proposta original de formar alunos dentro do espírito cooperativista; a partir de então, com a implantação do sistema EscolaFazenda nos colégios técnicos agrícolas do país, é que se passou a dar maior importância às Cooperativas-Escola, passando as mesmas a integrar a estrutura pedagógica da habilitação profissional do Técnico Agrícola.

O sistema Escola-Fazenda preconizava que, além de se atender aos princípios doutrinários, a Cooperativa-Escola deveria servir de órgão catalisador na execução de projetos de produção nas Escolas Técnicas Agricolas (ETAs), promover a defesa dos interesses comuns e realizar a comercialização da produção originária do processo de ensino agrícola.

Em 1975, a recém criada COAGRI (Coordenação Nacional de Ensino Agropecuário) estabeleceu que o papel principal das CooperativasEscola seria a provisão de recursos físicos, administrativos e pedagógicos paras as ETAs. Passou-se então a exigir das Cooperativas-Escola muito mais flexibilidade do que legalmente permitido; em 1982, isto foi reconhecido legalmente, e as Cooperativas-Escolas passaram a 
ter o mesmo tratamento legal dispensado às cooperativas tradicionais, como por exemplo, poder comprar e vender insumos e produtos no mercado, investir recursos de acordo com os desejos da assembléia, etc.

\section{Por que a escola deve ter uma Cooperativa educacional?}

Trabalhos de pesquisa recentes mostram que $65 \%$ dos produtores rurais participam de cooperativas, que são muito utilizadas para compra de insumos e comercialização da produção. A Cooperativa-Escola viria então preencher esta necessidade de se conhecer a filosofia, a estrutura e o funcionamento de uma cooperativa.

Ela deve servir, também, para desenvolver o sentido de responsabilidade nos alunos, já que eles estarão administrando o empreendimento. Deve-se, ainda, pensar no aspecto de trabalho em grupo e no desenvolvimento da capacidade de liderança.

Outros aspectos que adquirem importância na Cooperativa-Escola em virtude da estrutura administrativa das ETAs, dizem respeito à geração e administração de recursos. Uma estrutura burocrática muito rígida impede que os recursos fluam de acordo com as necessidades decorrentes da sazonalidade da produção agrícola.

A Cooperativa-Escola pode facilitar a administração destes recursos sob o controle do diretor, professores, alunos e comunidade.

\section{A COOPERATIVA EDUCACIONAL NA ESCOLA TÉCNICA-AGRÍCOLA DE INCON- FIDENTES, MG.}

\section{Breve histórico e estrutura administrativa da escola}

A Escola Agrotécnica Federal de Inconfidentes localiza-se na cidade de Inconfidentes, MG. Ela conta atualmente com 32 professores, 72 funcionários e 425 alunos praticamente de todo o Brasil, dos quais 396 moram nos alojamentos da Escola.

A atual estrutura administrativa da Escola é mostrada na figura 1.

As Unidades Educativas de Produção (UEPs) mudam sempre, mas de modo geral, contêm projetos em horticultura, culturas regionais, culturas perenes e temporárias, animais de pequeno porte (frango, coelho, etc.) e de grande porte (gado corte, gado leite), agroindústria $\mathrm{e}$ mecanização. Atualmente, a escola conta com 40 projetos, sendo que cada unidade executiva tem um professor responsável e pode conter diferentes projetos.

Cada UEP é administrada por um professor responsável e monitores escolhidos dentre os alunos. Deve-se ressaltar que os projetos têm que ter caráter eminentemente pedagógico, isto $\epsilon$, contribuir para a formação educacional do aluno.

Diretor Geral

Diretor-adjunto

Assessor

Chefe de gabinete

Chefe da unidade de processamento de dados

Secretária

Diretor do Departamento de Pedagogia e Apoio

Didático

Coordenador de Supervisão Pedagógica

Chefe do Setor de Biblioteca

Chefe do Setor de Atividades Artísticas e Culturais

Coordenador de Registros Escolares

Coordenador de Curso Técnico

Coordenador de Relações Empresariais

Coordenador de Orientação Educacional

Diretor do Departamento de Atendimento ao Educando

Coordenador de Alimentação e Nutrição

Coordenador de Assistência ao Internato

Chefe do Setor de Esporte e Lazer

Diretor do Departamento de Educação, Produção e Extensão

Coordenador de Cooperativa-Escola

Coordenadores das Unidades Educativas de Produção (Agriculturas I, II e III, Zootecnias I, II e III, Mecanização Agrícola, Agro-Indústria, Pesquisa e Extensão, Produção de Mudas e Jardins) Diretor do Departamento de Administração

Coordenador de Planejamento e Orçamento

Coordenador de Execução Orçamentária e Financeira

Coordenador de Serviço de Pessoal

Coordenador do Serviço de Atividades Auxiliares

Chefe do Setor de Almoxarifado

Chefe do Setor de Patrimônio

Chefe do Setor de Segurança e Vigilância

Figura 1. Estrutura administrativa da Escola Agrotécnica Federal de Inconfidentes, MG. 


\section{A Cooperativa-Escola}

O estatuto da Cooperativa-Escola dos Alunos da Escola Agrotécnica Federal de Inconfidentes Ltda. foi aprovado em $30 / 08 / 83$. Seus objetivos são educar os alunos dentro dos princípios do cooperativismo e servir de instrumento operacional dos processos de aprendizagem, apoiar a ação educativa da escola e ajudar na formação integral do técnico agrícola; atuar na aquisição de insumos em geral; realizar a comercialização e prestar outros serviços de conveniência dos associados. Uma representação esquemática da operacionalização da Cooperativa-Escola 6 apresentada na figura 2.

As Unidades Educativas de Produção (UEPs) são entidades organizacionais onde se desenvolvem os projetos educativos e de produção. Esses projetos servem para que os alunos utilizem conhecimentos adquiridos em sala de aula e tambêm, possibilitam a geração de novos conhecimentos que poderão ser utilizados em sala de aula.

A Cooperativa-Escola teria um papel quádruplo no processo:

1. fornecer insumos e serviços para as UEPs e comercializar a produção advinda destas;

2. possibilitar a prática do cooperativismo para os alunos da disciplina cooperativismo e também realimentar a disciplina com novos conhecimentos;

3. comercializar a produção das UEPs e, com a respectiva receita realimentar o processo de produção;

\section{4. fornecer produtos para o refeitório da Escola.}

É importante notar que existe uma disciplina denominada Cooperativismo onde os alunos são, desde $01^{\circ}$ ano, conscientizados sobre a importância do cooperativismo e da CooperativaEscola.

\section{Descrição do sistema}

O organograma da Cooperativa-Escola de Inconfidentes é mostrado na figura 3. A participação dos alunos na Cooperativa-Escola começa quando de sua matrícula na escola. Naquela oportunidade, lhes é oferecida a oportunidade de associar-se à cooperativa mediante o pagamento de uma pequena taxa. Além de administrada pelos alunos, a cooperativa conta com um professor coordenador que ocupa um cargo de confiança e é indicado pela diretoria, trabalhando em tempo integral, e uma contadora contratada pela cooperativa que tambem trabalha em tempo integral. Deve-se ressaltar que a lei só permite a contratação de um funcionário que neste caso, $\in$ a contadora.

A participação dos alunos se dá nas seguintes funções:

Diretoria (Presidente, Vice-Presidente, $1^{\circ}$ e $2^{\circ}$ tesoureiros, $1^{\circ}$ e $2^{\circ}$ gerentes, $1^{\circ}$ e $2^{\circ}$ secretários);

Conselho Fiscal ( 3 membros efetivos, 3 membros suplentes, escolhidos pela diretoria para fiscalizarem os projetos);

Conselho de Representates (6 membros, representando alunos de cada série; fazem a ligação da diretoria da cooperativa com os alunos do curso).

Anualmente, os alunos são incentivados a se reunirem e formarem chapas para eleição da diretoria da cooperativa. Os membros da diretoria e do conselho fiscal são eleitos e os membros do conselho de representantes, indicados. A participação de todos os alunos, no entanto, é incentivada, o que diminui a possibilidade de ocorrência de ilegalidades administrativas. Como todas cooperativas, a Cooperativa-Escola está sujeita a auditorias externas (MEC em Brasília e OCEMG em Minas Gerais). Ela também é associada ao sistema estadual e federal de cooperativas brasileiras. Estas associações têm programas de treinamento para administradores de cooperativas, conselho fiscal, etc.

A Cooperativa é um instrumento importante na administração dos recursos da escola. Anualmente, o professor encarregado da SEP (Seção de Educação e Produção), gerente da cooperativa, diretores e professores encarregados de projetos se reunem para definir prioridades de financiamentos dos projetos e tamanho e recursos dos mesmos. Em caso de discórdia sobre alocação de recursos, a palavra final é dada pelo Diretor do Departamento de Educação, Produção e Extensão.

$E$ interessante notar-se que a Cooperativa tem um acordo operacional com a Escola. Esta the repassa $30 \%$ dos recursos recebidos do Governo Federal na forma de insumos (adubos, ráção, sementes, etc.) e a Cooperativa assume o compromisso de fornecer alimentos de, aproximadamente, o mesmo valor para o refeitório. Óleo diesel, eletricidade, etc., a escola teria que comprar de qualquer forma e não são considerados insumos. 


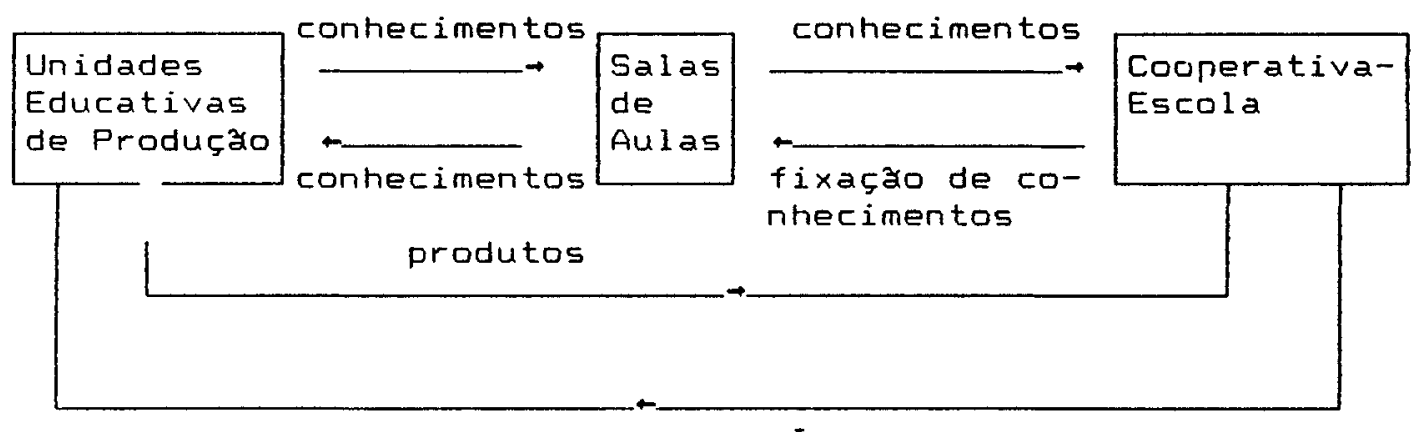

Insumos

Figura 2. Representação esquemática da proposta de atuação da Cooperativa-Escola de Inconfidentes, MG.

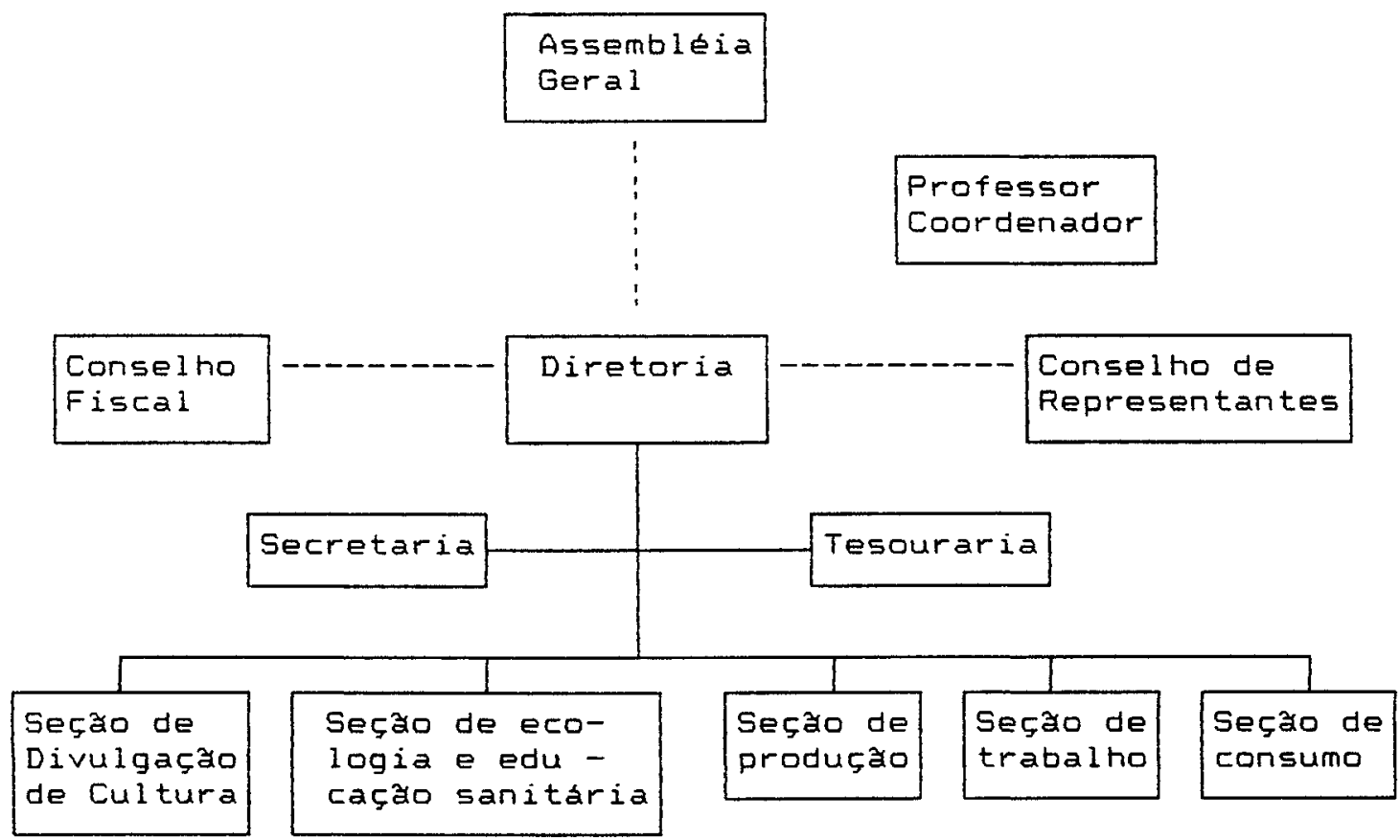

Figura 3. Organograma da Cooperativa-Escola dos alunos da Escola Agrotécnica Federal de Inconfidentes, MG.

Sci. agric., Piracicaba, 50(3):509-516, out./dez., 1993 
O maior problema neste sistema é que a produção encaminhada para o refeitório não é contabilizada ao preço de mercado.

Além do retorno na forma de alimentos para o refeitório, a cooperativa também paga alguns professores extras, auxilia na pintura e reforma da escola, etc.

Como parte do contrato operacional e quandc da criação da cooperativa, foi assinado um contrato, renovável a cada dois anos, onde a Escola cede em comodato para a cooperativa, prédios, máquinas e equipamentos e terras. Isto facilita a operacionalização da produção, uma vez que a cooperativa pode até mesmo trabalhar em parceria com terceiros.

A cooperativa procura contabilizar todos os custos de produção e acrescentar um mark-up de $20 \%$ para gerar uma sobra financeira. Estas sobras financeiras vão para o Fundo de Assistência Técnica, Educacional e Social (FATES) que ajuda em viagens, esportes, etc. Os custos de produção são calculados por cada professor individualmente, que contabiliza tudo, inclusive mão-de-obra. Entretanto, é um custo irreal pois a escola geralmente cede óleo diesel, eletricidade, além de quatro funcionários.

Além de comercializar a produção da escola, a Cooperativa-Escola comercializa para os alunos artigos de bazar, higiene pessoal, etc. Neste caso, a comercialização é feita ao preço corrente de mercado.

\section{ANÁLISE CRÍTICA DO SISTEMA COOPERA- TIVA-ESCOLA}

\section{Considerações sobre o sistema}

Apesar das contínuas crises econômicas e sociais do Brasil, a Cooperativa-Escola de Inconfidentes tem sido capaz de sobreviver de forma lucrativa. Além de funcionar como uma cooperativa na verdadeira acepção da palavra, o envolvimento dos alunos é grande, a cooperativa é rentável e se encontra em boa situação financeira. Ela é completamente auto-financiada e tem permitido à Escola investir em áreas que de outra forma seria impossível; atualmente, estão investindo num pequeno abatedouro, laticínio $\mathbf{e}$ numa pequena unidade de industrialização para processar pasta de alho, doces, conservas, etc. Além disso, sobras de caixa são utilizados para enviar alunos e professores para programas de treinamento, congressos, etc.
A flexibilidade no uso dos recursos e geração dos mesmos também mantém o corpo docente e discente motivados. Eles sentem que a manutenção da qualidade do programa e o alcance de novas conquistas na escola dependem grandemente de seu esforço. Além disso, sobras de caixa são empregados em amenidades que motivam alunos e professores tais como antena parabólica, aparelho de televisão e vídeo cassete, esportes, etc.

Resumidamente, pode-se dizer que 0 programa alcança seus objetivos, tanto na forma acadêmica, porque realimenta o responsável pela disciplina de cooperativismo com novos fatos sobre administração de uma empresa real, quanto na aplicação prática dos ensinamentos de cooperativismo aprendidos em classe.

Existem alguns poucos pontos fracos do sistema que merecem ser salientados e comentados:

- as atividades de uma escola não visam primordialmente o lucro, tendo-se que buscar um balanceamento entre educação e prática, o que às vezes impede o aproveitamento total do potencial da cooperativa. Assim, por exemplo, uma certa atividade pode ter maior potencial lucrativo, mas como os alunos têm por necessidade curricular que acompanhar outras culturas, isto pode prejudicar a lucratividade da cooperativa.

- os professores são responsáveis pelo andamento de seus projetos, mas, paradoxalmente, eles serão criticados pelas perdas, mas não serão recompensados por eventuais ganhos excedentes. Como as atividades de produção envolvem muito empenho dos professores, isto às vezes, lhes resulta em certo prejuízo pessoal. Fica, então, a questão sobre até onde eles estarão dispostos a arcar com estes prejuízos pessoais.

- é muito complicada a coordenação entre atividades de aula e as atividades de campo, inclusive no que diz respeito à administração da cooperativa;

- apesar do intuito motivador de aprendizado, a cooperativa não funciona realmente como uma cooperativa porque: (a) a responsabilidade e a autoridade dos alunos na administração da cooperativa é limitada; (b) existem limitações na delegação de autoridade para os alunos; por exemplo, alunos menores de 18 anos não podem preencher notas de vendas; (c) é clara e nítida a influência do professor coordenador na administração da cooperativa; (d) certas atividades 
produtivas, mesmo que não sejam as mais lucrativas, têm que ser financiadas pela cooperativa porque fazem parte do programa de aprendizado dos alunos; (e) não existe uma cobrança dos associados no sentido da cooperativa operar no máximo de eficiência econômica.

- existe muito poder nas mãos do professor coordenador da cooperativa;

\section{Análise crítica do sistema}

À seguir, destacam-se alguns pontos que ao nosso ver favorecem o bom funcionamento da Cooperativa-Escola na Escola Agrotécnica Federal de Inconfidentes:

- a estrutura organizacional da escola é complexa porém muito boa, permitindo que todos os participantes compreendam suas funções $e$ as interrelações dentro da estrutura. Sem dúvida nenhuma, grande parte do mérito pode ser destinado ao atual diretor, que soube identificar pessoas, delegar responsabilidades e cobrar resultados;

- apesar de não haver uma descrição por escrito das funções de cada elemento dentro do sistema, professores, alunos e funcionários conhecem suas obrigações;

- o processo de planejamento também é bom uma vez que leva em consideração, dentro dos limites ditados pelas necessidades de aprendizagem, o possível retorno financeiro de cada atividade agropecuária. Também, os cooperados têm a oportunidade de opinar sobre as atividades que serão desenvolvidas pela cooperativa;

- há um esforço constante da administração da escola no sentido de identificar e desenvolver novas lideranças entre os alunos;

- existe um bom fluxo de informações entre a administração da escola e os alunos, de forma que eles sabem o que se está fazendo para alcançar os objetivos planejados;

- os alunos sentem pessoalmente os benefícios da cooperativa;

- há a preocupação de que o trabalho dos alunos não seja explorado; isto é, eles têm atividades para desempenhar, mas isto não pode comprometer o aspecto educacional;

- o processo é constantemente avaliado, sendo que anualmente novas culturas ou atividades são adicionadas ou retiradas, etc.;

- através de reuniões entre responsáveis pelos projetos, cooperativa e diretoria da escola, procurase chegar a um concenso sobre as atividades que devem ser executadas com os recursos da cooperativa;

- as decisões são tomadas com base nos recursos existentes e projeções para novos recursos;

- membros da diretoria da cooperativa sentem que são parte importante do processo de decisão.

\section{SUGESTÕES PARA OUTRAS ESCOLAS}

Praticamente, todos os procedimentos vistos nesta Escola podem ser recomendados para outras escolas desejosas de implantar o sistema de Cooperativa-Escola. Deve-se destacar, porém, as qualidades administrativas da diretoria da escola, que esteve disposta a ceder poder para professores, funcionários e alunos e a acatar suas sugestões. De um modo geral, deve-se destacar a necessidade de:

(a) boa organização estrutural, com funcionários e professores bem motivados;

(b) coordenar muito bem as atividades de campo com as atividades desenvolvidas na sala de aula;

(c) discutir e prioritizar a alocação de recursos gerados pela cooperativa entre os diferentes projetos;

(d) os membros da diretoria da cooperativa precisam conhecer suas funções, ser treinados e .receber orientação, ter autoridade e responsabilidade;

(e) é preciso que haja um sistema que coordene a discussões e tenha autoridade para decidir sobre a alocação de recursos;

(f) é preciso que se faça a real contabilidade de custos e de transferência de recursos da escola para a Cooperativa-Escola; 
(g) a administração da cooperativa, incluindo o professor orientador, precisa ser constantemente avaliada;

(h) É preciso que haja flexibilidade na alocação dos recursos, podendo os mesmos serem transferidos entre atividades e de acordo com as necessidades de caixa;

(h) as pessoas envolvidas no processo precisam saber o que e porque as coisas estão acontecendo.

Finalmente, é preciso salientar-se que a importância da cooperativa não se esgota na mera atividade de gerenciadora de recursos. Mesmo que esta necessidade venha a desaparecer, ainda ficará o importante papel de desenvolvimento de responsabilidade, liderança e da disseminação dos ideais do cooperativismo.

\section{REFERÊNCIAS BIBLIOGRÁFICAS}

BRASIL. Ministério da Educação e Cultura. Educação Agricola, 20 grau, linhas norteadoras. Brasilia: COAGRI, 1984a.
BRASIL. Ministério da Educação e Cultura Retrospectiva histórica do ensino agricola de $2^{\circ}$ Grau - PAPEL DA COAGRI. Brasilia: COAGRI, $1984 b$.

BRASIL. Ministério da Educaçãoe Cultura. Diretrizes de fumcionamento de uma escola agrotécnica federal. Brasilia: COAGRI, 1985. (Série Ensino Agrotécnico, 1).

DOMICIANO, c.S. A cooperativa-escola e sua importância no sistema escola-fazenda. Machado: 1991.

ESCOLA AGROTECNICA FEDERAL DE INCONFIDENTES. Estatuto da Cooperativa Educacional da E.A.F. de Inconfidentes. Inconfidentes, 1983.

ESCOLA AGROTÉCNICA FEDERAL DE INCONFIDENTES. Regimento interno. Inconfidentes, s.d.

Enviado para publicação em 08.03 .93 Aceito para publicaçāo em 12.05 .93 